
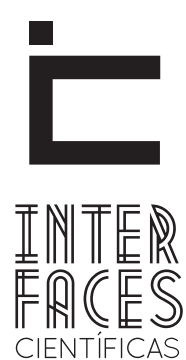

EDUCAÇÃO

ISSN IMPRESSO 2316-333X

ISSN ELETRÔNICO 2316-3828

\title{
CONTRIBUIÇÕES DE MARTINHO LUTERO À EDUCAÇÃO
}

Simone Varela ${ }^{1}$

\section{RESUMO}

O objetivo deste trabalho é o de contribuir para as discussões da História da Educação, referentes à alteração da lógica medieval ocorrida a partir dos séculos XII e XIII; suas influências na atuação da Igreja Católica do referido período; o posicionamento de Martinho Lutero diante das ações da Igreja Católica e, principalmente, os reflexos do pensamento de Martinho Lutero para a educação. O filme Lutero se constituiu como objeto para a análise contida neste trabalho que tem como referencial teórico a Nova História (LE GOFF, 2004; FRANCO JÚNIOR, 1980). A essência das concepções de Lutero sobre a educação evidencia a sua defesa do direito à educa- ção e, deste modo, a responsabilidade do Estado na promoção da educação para todos. Assim, percorrer a trajetória de Martinho Lutero durante a Reforma Religiosa resgata um momento ímpar na construção do pensamento educacional a partir do século $\mathrm{XVI}$ que se apresenta como um tema ainda bastante polêmico e político no século XXI: o acesso e a permanência na educação.

\section{PALAVRAS-CHAVE}

Martinho Lutero. Reforma Protestante. Direito à Educação. 


\section{ABSTRACT}

The objective of this work is to contribute to the discussions of the History of Education, regarding the amendment of medieval logic occurred from the twelfth and thirteenth centuries; their influences on the performance of the Catholic Church of that period; positioning of Martin Luther on the actions the Catholic Church, and especially the reflections of the thought of Martin Luther for education. The movie Luther was constituted as an object for analysis in this work that has as its theoretical framework the New History (LE GOFF, 2004; FRANCO JR, 1980). The essence of Luther's ideas on education reflects its defense of the right to education and thus the responsibility of the State in promoting education for all. So go the path of Martin Luther during the Reformation rescues a unique moment in the construction of educational thought from the sixteenth century that presents itself as a still quite controversial and political issue in the twenty-first century: access and permanence in education.

\section{KEYWORDS}

Martin Luther. Protestant Reformation. Right to Education.

\section{RESUMEN}

El objetivo de este trabajo es dar su aporte a los debates de la Historia de la Educación, respecto a modificación de la lógica medieval, producida a partir de los siglos XII y XIII; su influencia en el rendimiento de la Iglesia Católica de ese período; posicionamiento de Martin Lutero sobre las acciones la Iglesia Católica y en especial los reflejos del pensamiento de Martín Lutero para la educación. La película Lutero fue constituido como objeto de análisis en este trabajo que tiene como marco teórico de la Nueva Historia (LE GOFF, 2004; FRANCO JR. 1980) - La esencia de las ideas de Lutero sobre la educación, refleja su defensa del derecho a la educación, y por lo tanto, la responsabilidad del Estado en la promoción de la educación para todos. Así que, el camino de Martin Lutero durante la Reforma, rescata un momento único en la construcción del pensamiento educativo del siglo XVI que se presenta como un tema, todavía, muy contradictorio a la política del siglo XXI, y al acceso y la permanencia en la educación.

\section{PALABRAS CLAVE}

Martin Luther. Reforma protestante. Derecho a la educación. 


\section{INTRODUÇÃ̃O}

"Como uma religião que opõe tradicionalmente Deus e o dinheiro, poderia justificar a riqueza, sobretudo a riqueza mal adquirida?” (LE GOFF, 2004, p. 6). Este questionamento e outros feitos por Jacques Le Goff(2004) em seu livro, A bolsa e a Vida, se constituem como o ponto de partida para a compreensão do Universo e/ou contexto sócio histórico no qual, Martinho Lutero (1483-1546) ${ }^{1}$ obteve a sua formação acadêmico-religiosa e ideológica. Diga-se de passagem, formação esta envolta sob o manto sagrado dos valores e dogmas católicos difundidos ao longo da Idade Média e início da Modernidade.

Deste modo, percorrer a trajetória na qual ocorreu a alteração da lógica religiosa medieval ocidental relacionada aos pecados que envolviam as questões econômicas, que se deu a partir dos séculos XII e XIII, se constitui como a base para o entendimento das ações da Igreja Católica da época, liderada pelos Papas Júlio II (1503-1513) e Papa Leão X (1513-1521)², retratada no Filme Lutero. Os referidos papas estiveram à frente da Igreja Católica Apostólica Romana nos momentos, o primeiro deles, no qual Lutero passou a questionar as ações da Igreja Católica e o segundo, no rompimento de Lutero com a Igreja Católica, ou seja, a concretização da Reforma Protestante ${ }^{3}$ e suas concepções e ações relacionadas à educação.

1. Martinho Lutero nasceu em 1483, na cidade de Eisleben, cidade pertencente ao atual Estado alemão, Saxônia Anhalt. Em 1546 faleceu na mesma cidade. A este respeito ver in Rosa (1971).

2. Vianna (2011) apresenta o contexto histórico e a conjuntura política da Alemanha a partir de 1517, data na qual Martinho Lutero apresentou as 95 Teses para em seguida, tecer uma análise sobre o sermão "Sobre a Autoridade Secular" de 1523.

3. É importante considerar que algumas ideias reformistas relacionadas às críticas contra a Igreja Católica tiveram outros expoentes anteriores a Lutero. A este respeito Lopes (2007) explica que sob a influência de John Wycliff (1328-1384), professor e teólogo da Universidade de Oxford que iniciou a tradução da bíblia para o inglês e condenava a autoridade papal, John Huss (1369-1415), reitor na Universidade de Praga, foi condenado à morte pela Inquisição por continuar as ideias de Wycliff e morreu queimado em 1415. Todavia, conforme explica Franco Júnior (1980) a Reforma Protestante teve em Lutero, a partir de suas críticas iniciais contrárias às vendas de indulgências e relíquias, posteriormente com a publicação das 95 Teses (1517) e, finalmente com a instituição de uma nova Igreja, a concretização e notoriedade do movimento reformista.

\section{2 “RETRATOS” DO FILME: DIVERGÊNCIAS ENTRE OS PENSAMENTOS DE LUTERO E DA IGREJA CATÓLICA}

A lógica mencionada anteriormente é justamente aquilo que Le Goff (2004, p. 5) nomeia de "o parto do Capitalismo", ou seja, o momento, mais especificamente em finais do século XII, no qual a igreja católica inventou uma palavra chamada Purgatório ${ }^{4}$. Com a instituição do Purgatório o processo de salvação que era controlado pela Igreja Católica se tornou mais complexo e ao mesmo tempo esperançoso. A partir dele, que ocorreria antes do Juízo Final, as pessoas teriam a chance de expurgar os seus pecados e chegar aos Céus.

Além disso, esta relação de triagem entre Céu, Inferno e Purgatório, feita pela Igreja Católica, acabava por expurgar muitos pecados até então difíceis de remissão. Um deles é o caso dos usurários, considerados como a pior espécie de mercadores. Eram pessoas consideradas pecadoras pelo fato de terem enriquecido por meio de práticas econômicas que envolviam a venda do tempo, isto é, a cobrança de juros numa relação muito tênue entre o lícito e o ilícito.

Até a invenção do Purgatório, Le Goff (2004, p. 85) explica como funcionava o sistema tradicional de remissão dos pecados do usurário que poderia ocorrer durante a vida e até na hora da morte que consistia basicamente na "[...] confissão, contrição (arrependimento) e satisfação (penitência). No caso dele, a penitência era a restituição".

Ocorre que com uma contrição verdadeira, o usurário poderia até se salvar, mas seria necessário que ele pudesse pagar a penitência e o Purgatório passou

\footnotetext{
4. A alteração do pensamento religioso ocidental ocorreu de modo processual, por exemplo, a própria concepção de pecado e de penitência no período do entre os séculos XI ao XIII, passou por um processo de interiorização e deveria ser medido pela intenção do pecador. A criação do Purgatório é parte do referido processo.
} 
a ser esta penitência. Ao final das contas, o Purgatório significava o único caminho à salvação. Viúvas, filhos, netos, enfim, a família poderia, a partir de então, rezar e restituir, com o propósito "de salvar o usurário ao preço de qualquer indulgência” (LE GOFF, 2004, p. 82). Deste modo, assegurava-se, ao usurário e, também, a todos os pecadores que as famílias pudessem pagar às penitências, a salvação, ou seja, o Paraíso. 0 Purgatório configurou-se muito mais do que o local para expurgar os pecados. Significou a libertação dos pecadores, por meio da compra das indulgências, de um destino até então certo: o Inferno.

\begin{abstract}
Os Poetas chegam à beira do sétimo círculo. Sufocados pelo mau cheiro que se levanta daquele báratro, param atrás do sepulcro do papa Anastácio. Virgílio explica a Dante a configuração dos círculos infernais. 0 primeiro, que é o sétimo, é o círculo dos violentos. [...]. O segundo círculo, que é o oitavo, é o dos fraudulentos e se compõe de dez círculos concêntricos. 0 terceiro, que é o nono, se divide em quatro compartimentos concêntricos. Fala-lhe também acerca dos incontinentes e dos usurários. Movem-se depois para o lugar de onde se desce para o precipício. [...]. Saindo do Inferno, Dante respira novamente o ar puro e vê fulgentíssimas estrelas. Encontra-se na ilha do Purgatório. [...] Dante eleva-se de um céu para outro, e em cada um deles aparecem-lhe espíritos bem-aventurados que, quando vivos, possuíram a virtude própria do respectivo planeta. (ALIGHIERI, 2003, p. 88; 268; 525).
\end{abstract}

A invenção do Purgatório incrementou a venda de indulgências que a Igreja Católica cometia, pois, seria difícil retirar do Inferno alguém que teoricamente já havia sido condenado. Logo, vender o pedacinho do céu para alguém que já morreu (por meio de seus entes queridos) se constituiu na ampliação de um negócio que já era ótimo, isto é, a venda da indulgência efetuada antes da pessoa morrer. Esta é uma das ações abusivas que a Igreja Católica cometia no período (século XVI) retratado no filme Lutero.

Já no início do filme, Lutero durante uma visita a Roma, em $1510^{5}$, observa uma realidade que muito se assemelha com a ideia que se faz do Inferno, ou

5. A este respeito ver Cambi (1999). como queiram, do Purgatório. Uma cidade repleta de problemas sociais, econômicos e educacionais e uma Igreja Católica corrupta que evidenciava a prática abusiva da venda de indulgências, de relíquias e de outros instrumentos religiosos sob seu domínio, como as missas encomendadas, por exemplo, com a promessa da salvação eterna (Paraíso) para o povo bastante sofrido e miserável.

Sobre a afirmação de que os questionamentos de Lutero o fizeram acreditar que ele estivesse realmente perdendo a fé como é sugerida no filme, não se pode sentenciar. Mas, o que de fato ocorreu foi à divergência do pensamento de Lutero com o pensamento da Igreja Católica sobre as diretrizes, os dogmas e o próprio entendimento da Bíblia, e em especial, sobre a remissão dos pecados pelas indulgências.

Ao aprofundar os seus estudos em Teologia, na Universidade de Wittenberg ${ }^{6}$, enviado pelo VigárioGeral da Ordem dos Agostinianos, Johann Von Staupitz, Lutero aprofundou, também, suas críticas em relação à Igreja Católica seja durante os sermões em suas missas ou durante as aulas que passou a ministrar na Universidade de Wittenberg, fundada pelo príncipe Frederico III da Saxônia.

82 Por exemplo: por que o papa não evacua o purgatório por causa do santíssimo amor e da extrema necessidade das almas - o que seria a mais justa de todas as causas -, se redime um número infinito de almas por causa do funestíssimo dinheiro para a construção da basílica - que é uma causa tão insignificante? (LUTERO, 1517, p. 18)

Como não poderia ser diferente, a Igreja Católica se sentiu incomodada e desafiada por Lutero. Naquele momento, a Igreja Católica já estava sob o papado de Leão X (1513-1521) que incrementou a venda de indulgências para finalizar a construção da Basílica

\footnotetext{
6. Lienhard (1998) explica que a Universidade Martinho Lutero de Halle-Wittenberg, resultou na junção da Universidade do Halle e Wittenberg. Ela é localizada nas cidades Halle an der Saale e Wittenberg, pertencentes ao Estado Saxônia-Anhalt, na Alemanha. Link para o site da Universidade: http://www.uni-halle.de/.
} 
de São Pedro, em Roma, como uma tentativa de reerguer a imagem da Igreja Católica.

Lutero foi chamado a Roma para revogar as suas afirmações contrárias à Igreja Católica. Ele foi acusado de ensinar novas doutrinas, dentre elas, a questão da venda das indulgências. Lutero não revogou as suas afirmações e passou a ser perseguido pelos líderes da Igreja Católica, principalmente após publicar e afixar as suas 95 Teses na Igreja do Castelo.

Obteve a proteção do Príncipe Frederico III, da Saxônia, também, chamado de Frederico, o sábio que o protegeu por admirar a genialidade de Lutero em suas argumentações durante as aulas e palestras que ministrava na Universidade de Wittenberg.

Sob pressão da Igreja Católica, Frederico III não conseguiu evitar que Lutero fosse intimado a depor diante de líderes políticos e religiosos, acusado de heresia. Mas, conseguiu que o julgamento ocorresse em solo Alemão e não em Roma. O julgamento ocorreu na cidade de Worms ${ }^{7}$, em 1521. A importância do julgamento ocorrer na Alemanha, significava que Lutero, além de ser alemão, estava desde a sua ordenação como sacerdote, falando e escrevendo com o povo alemão em alemão. As suas missas eram em alemão, as suas aulas e palestras também.

Este fato dificultou que Lutero fosse para a fogueira da Inquisição, pois, o povo alemão apoiou Lutero, o Príncipe Frederico III o ajudou novamente, dando-lhe abrigo $^{8}$ e conseguiu que a Saxônia estivesse isenta do Édito de Worms ${ }^{9}$. Em seguida, Lutero foi excomunga-

7. Lienhard (1998) explica que Worms foi a cidade na qual houve o julgamento de Lutero em 1521. Este evento é também chamado de Dieta de Worms, na qual estiveram presentes os representantes dos líderes da Igreja Católica e no campo político, o Imperador Carlos V.

8. Lutero permaneceu aproximadamente um ano exilado no Castelo de Watburg, na cidade de Eisenach.

9. O Édito de Worms também é chamado de édito de Carlos por Rosa (1971) que explica que este documento considerava Lutero fora da Lei. O Príncipe Frederico III da Saxônia conseguiu que Lutero fosse ouvido pela Dieta de Worms e enquanto Lutero não foi autorizado a voltar para a vida pública, o protegeu. Além disso, existiam conflitos que ocupavam e preocupavam o Imperador do Sacro-Império Romano Germânico, Carlo do pela Igreja Católica e deu continuidade à Reforma Protestante. Nela, o próximo passo foi à tradução da bíblia para o alemão realizada enquanto esteve exilado em Eisenach.

As ideias de Lutero haviam se espalhado e doze freiras fugiram do convento Nimbschen. Esta é a última questão que chama atenção no filme Lutero. Ela é sobre a presença feminina na vida dos religiosos. Mais uma divergência entre Lutero e a Igreja Católica, o celibato. Lutero se casou com uma das ex-freiras fugitivas do convento, Catarina Von Bora.

\section{LUTERO E A EDUCAÇ̃̃O}

Há controversas historiográficas sobre a vida e a obra de Martinho Lutero, sobre sua posição, por exemplo, em relação aos judeus ${ }^{10}$ e inclusive sobre a imagem de Lutero veiculada pelo filme dirigido por Eric Till. Além disso, sabe-se que a Reforma Religiosa encabeçada por Martinho Lutero, resultou na organização de novas religiões, que ao longo do tempo difundiram outras religiões dissidentes do Protestantismo e que autores contrários ou adeptos a esta ou àquela orientação religiosa também contestaram, ou apoiaram as análises de Martinho Lutero. Controvérsias a parte, não que elas não sejam enriquecedoras à pesquisa e ao conhecimento científico-acadêmico, mas recorrendo a discussão de Hobsbawm (1998) sobre a historiografia, e inserida nela a dificuldade de algumas correntes historiográficas diferenciarem fato de ficção. Assim, é necessário categorizar: “[...]

\footnotetext{
V. Os conflitos internos foram um dos problemas do Império Romano tanto Ocidental (queda em 476) quanto o Império Romano do Oriente (queda em 1453). A tentativa de romanizar culturas e etnias diferentes obrigando-as a respeitar as leis e a religião característica do Império Romano. Já os conflitos externos, isto é a corrida pela conquista e domínio de territórios resultou, em conflitos maiores e posteriores como a Guerra Franco-Prussiana (1870-1871), na qual a França cede à Alemanha (unificada) o território de Alsácia-Lorena. Anos depois o movimento do imperialismo expandia-se e um dos motivos da Primeira Guerra Mundial (1914-1918) foi a retomada do território de Alsácia-Lorena, embora a causa imediata tenha sido o assassinato do Príncipe Herdeiro do trono austríaco Francisco Ferdinando. 10. A Este respeito ver Rieth (2013).
} 
Elvis Presley está morto ou não" (HOBSBAWM, 1998, p. 18). Portanto, infere-se que há fatos históricos sobre a vida de Lutero que de fato ocorreram. Assim, o objetivo aqui é o de refletir sobre esses momentos históricos vividos por Lutero e, a partir deles, sobre o papel de Lutero na Educação.

É possível afirmar que a Reforma Religiosa difundida por Lutero permitiu ao cristão a possibilidade de adquirir, conforme explica Cambi (1999, p. 248),

\section{[...] instrumentos elementares da cultura (em particu- lar a capacidade de leitura) e, de maneira mais geral, para as comunidades religiosas, a necessidade de di- fundir essa posse em nível popular, por meio de ins- tituições escolares públicas mantidas a expensas dos municípios.}

Lutero reformou a religião e participou do início da organização da educação moderna pública. As duas preocupações de Lutero, celebrar a missa no idioma do cristão e a possibilidade dele ler a bilia, acabaram, no mínimo por democratizar o ensino que ao longo de toda a Antiguidade e Idade Média, sempre esteve restrito a pequenos grupos representantes de classes sociais mais privilegiadas pela sociedade. A prática da Igreja Católica antes da Reforma Religiosa estava restrita, em se tratando do ensino popular, pela repetição de rituais nas cerimônias religiosas realizadas em latim e no ensino pelas imagens (pinturas, estátuas, vitrais) amplamente presentes nos templos religiosos católicos.

Cabe mencionar que o movimento da Reforma Religiosa é parte integrante do Renascimento, portanto de caráter Humanista. Todavia, Cambi (1999, p. 246) explica que a educação e a pedagogia foram "além das 'rupturas' do humanismo formando uma civilização pedagógica nova, doravante decididamente encaminhada para as características da Modernidade, embora estas só sejam decantadas plenamente no século seguinte".

Na relação entre a Reforma Religiosa e o Humanismo ocorrem diferenças e/ou a ampliação de pontos que caracterizam a Reforma Religiosa não abarcados pelo Humanismo. Luzuriaga (1979, p. 109) chama atenção para as diferenças entre a Reforma Religiosa e o Humanismo, das quais se destacam as diferenças que virão a seguir.

A Reforma, igualmente, organiza a educação pública não apenas no grau médio, ampliando a ação dos colégios humanistas da Renascença, mas também, e pela primeira vez, com a escola primária pública. Finalmente, tem a Reforma caracteres próprios em cada país, acentuando o caráter nacional da educação, e daí surgem diversos sistemas nacionais, ante a universidade e homogeneidade da educação medieval. Cabe mencionar aqui fato decisivo para a educação: o emprego dos idiomas vernáculos, nacionais, em vez do exclusivo latim, como ocorria no ensino anterior.

Ao se tratar do caráter público dos diferentes níveis de escolarização do modelo de educação proposto a partir da Reforma Religiosa, adentra-se em questões referentes às origens do direito à Educação. Barbosa (2011) explica que é comum a produção científica apresentar o surgimento da educação como um direito social a partir processo da Revolução Francesa que ocorreu em finais do século XVIII. Apesar disso, Barbosa (2011, p. 868) analisa que dois séculos antes, e a partir da especificidade do modelo de educação proposto por Lutero, é possível perceber "[...] as ações de Martinho Lutero como o grande propulsor da defesa do Estado, como o responsável pela educação escolar”.

A este respeito Cambi (1999, p. 248) analisa que a partir do movimento do protestantismo,

\begin{abstract}
[...] afirmam-se em pedagogia o princípio do direito-dever de todo cidadão em relação ao estudo, pelo menos no seu grau elementar, e o princípio da obrigação e da gratuidade da instrução, lançando-se as bases para a afirmação de um conceito autônomo e responsável de formação, não estando mais o indivíduo condicionado por uma relação mediata de qualquer autoridade com a verdade e com Deus.
\end{abstract}

Lutero evidencia em sua concepção de educação o princípio do direito à educação em diversas mani- 
festações e solicitações aos dirigentes da Alemanha, como na Carta aos conselheiros comunais de todas as cidades da Alemanha (1524) ${ }^{11}$; no Sermão sobre a necessidade de mandar os filhos à escola (1530) ${ }^{12}$, além de outros escritos de caráter religioso como o Grande e pequeno catecismo (1529). A este respeito, Cambi (1999, p. 249) afirma que a concepção pedagógica de Lutero "[...] baseia-se num fundamental apelo à validade universal da instrução, a fim de que todo homem possa cumprir os próprios deveres sociais".

Barbosa (2011, p. 871) destaca o significado do posicionamento de Lutero em se tratando do direito à educação:

[...] o caráter estatal que atribui à educação, não somente rompendo o monopólio da Igreja Católica, como mudando as estruturas da sociedade da época ao apresentar o Estado como o responsável pela educação escolar que deveria ser para todos e de frequência obrigatória. Para ele, tanto o financiamento, organização e supervisão das escolas deveriam ser de responsabilidade pública [...].

Deste modo, a atribuição ao dever das autoridades municipais em manter as instituições escolares, além de criá-las, conforme explica Cambi (1999) parte do princípio estabelecido por Lutero de que cristãos deveriam ser educados religiosamente e, para isso, a necessidade imperativa da alfabetização/letramento para a leitura da bíblia. Fato que também significava para Lutero a preparação de futuros e bons resultados a toda à sociedade: "[...] a formação de cidadãos cultos e respeitadores da lei favorece a paz social e uma grande economia de dinheiro" (CAMBI, 1999, p. 249).

11. Barbosa (2011, p. 870) apresenta um texto anterior produzido por Lutero, em 1520, que já evidencia preocupações educacionais e fora intitulado "À nobreza cristã da nação alemã, acerca da melhoria do estamento cristão". Esta mesma autora intitula, diferentemente de Cambi (1999), a carta escrita aos conselhos das cidades alemãs como "Aos conselhos de todas as cidades da Alemanha para que criem e mantenham escolas cristãs", de 1524

12. Este Sermão é intitulado "Uma prédica para que se mandem os filhos à escola”, de 1530, conforme argumenta Barbosa (2011, p. 870).
A base do modelo educacional proposto por Lutero estava pautado no ensino das línguas e organização da escola fundamentada em quatro setores.

[...] o das línguas (latim, grego, hebraico, alemão), para remontar às fontes das Sagradas Escrituras; o das obras literárias (pagãs e cristãs), para o ensino da gramática e a leitura dos textos sagrados; o das ciências e das artes, e o da jurisprudência e da medicina. (CAMBI, 1999, p. 249).

Cabe mencionar que o professor cumpria um papel importante em se tratando do caráter formativo do aluno e por isso precisava "[...] possuir em justo equilíbrio severidade e amor” (CAMBI, 1999, p. 250).

Luzuriaga (1979), Barbosa (2007) e Cambi (2009), explicam que no processo de reorganização das escolas municipais e escolas secundárias mantidas pelo estado, como, também, a criação dos ginásios, tiveram a participação de outros seguidores da Reforma Religiosa iniciada por Lutero, na Alemanha. Filipe Melanchton (1497-1560) ${ }^{13}$ é, por exemplo, considerado por Cambi (1999, p. 250) como o responsável pela “[...] elaboração das estruturas organizativas e dos conteúdos culturais próprios das escolas secundárias da Reforma [...]". Além, de introduzir na Universidade uma forma de ensino diferente da eclesiástica para o ensino "[...] sobre os clássicos gregos e latinos" (BARBOSA, 2007, p. 166).

Há outros colaboradores de Lutero destacados por Luzuriaga (1979, p. 115) como participantes da Reforma Religiosa e atuantes nas mudanças relacionadas à educação alemã.

Valentin Trotzendorf, [...] introduziu um princípio de autonomia escolar, em forma de República romana, no Colégio de Goldberg; Johannes Sturm [...], o mais importante dos reitores do Colégio humanista [...]; Ulrich

13. A este respeito Barbosa (2007, p. 166) explica que Lutero e Melanchton se conheceram em 1518. "Melanchton o teria acompanhado durante todas as fases da Reforma, tornando-se uma pessoa fundamental para Lutero no período em que traduziu a Bíblia e servindo de consultor sobre o grego e sobre as passagens bíblicas". 
Zwinglio [...], precursor de Calvino e autor do primeiro livro sobre educação do ponto de vista protestante.

Johannes Bugenhagen é considerado por Luzuriaga (1979, p. 115) como um "[...] inspirador da escola secundária pública, [...] principal criador da escola primária”. Ele destaca-se no campo das escolas primárias por ser: “[...] responsável pela inspiração de uma série de ordenações municipais no norte da Alemanha onde ele, em processo de reorganização das igrejas da região, estabelece diversos preceitos sobre a educação pública” (BARBOSA, 2007, p. 167).

Luzuriaga (1979, p. 111) explica que ao final do século XVI, a educação na Alemanha estava organizada da seguinte maneira:

a) escolas primárias para o povo, nas aldeias e pequenas localidades, com ensino muito elementar dado na língua alemã, por eclesiásticos ou sacristãos, e com caráter principalmente religioso; b) escolas secundárias ou latinas, para a burguesia, de caráter humanista, mas também religioso, como preparação principalmente para os cargos eclesiásticos e profissões liberais; c) escolas superiores e universidades já existentes em parte, mas transformadas no espírito da religião reformada, e outras, de nova criação dos príncipes protestantes.

A Reforma Religiosa não esteve restrita à Alemanha e nem ao pensamento de Lutero. Ela teve outros líderes com especificidades que posteriormente resultaram em outras religiões e outros modelos educacionais. João Calvino (1509-1564) ${ }^{14}$ foi responsável pela Reforma Protestante, inicialmente na Suíça. Embora, posteriormente, conforme argumenta Luzuriaga (1979), suas ideias foram difundidas em outros países e continentes, como na França, Holanda, Bélgica, Inglaterra e colônias inglesas da América. Henrique VIII foi o responsável pela difusão do anglicanismo, na Inglaterra onde, foram fundados colégios, "[...] para os filhos da burguesia, e dos cavaleiros pobres; os ricos eram edu-

14. João Calvino era francês, mas foi obrigado a fugir para a Suíça em função de perseguições aos seguidores das religiões protestantes. A este repeito ver in Cambi (1999). cados por preceptores" (LUZURIAGA, 1979, p. 114).

\section{CONSIDERAÇÕES FINAIS}

Apesar do movimento da Reforma Religiosa não estar restrito à Alemanha, é inegável o papel desempenhado por Lutero no que se refere ao acesso à educação.

As alterações no modelo socioeconômico que ocorreram em finais da Idade Média, sinalizaram a transição para um modelo de sociedade que conhece bem: o Capitalismo. No bojo das transformações, estavam as divergências de Lutero com a Igreja Católica do período mencionado e suas preocupações e o seu interesse na fundação de escolas para a melhoria da educação religiosa, fatos que contribuíram para a ampliação do acesso à educação.

A essência dos princípios das propostas de Lutero para a Educação consiste na defesa de uma escola para todos e de caráter obrigatório. Quatro séculos após a Reforma Religiosa e a implementação das propostas pedagógicas de Lutero na Alemanha, pode-se ainda perceber que o acesso para todos à educação não ainda é um desafio para muitos países. Em se tratando do Brasil, a atual Lei de Diretrizes e Bases da Educação Brasileira, a LDB 9.394/96 prevê em seu artigo $4^{\circ}$ o dever do Estado em relação à educação: “O dever do Estado com educação escolar pública será efetivado mediante a garantia de: [...] educação básica obrigatória e gratuita dos 4 (quatro) aos 17 (dezessete) anos de idade" (BRASIL, 1996, p.3). Todavia, a realidade brasileira ainda evidencia que a garantia ao acesso e a permanência à escola depende, também, de políticas públicas que precisam ser implementadas.

O Brasil tem 13,9 milhões de analfabetos adultos, segundo levantamento feito entre 2005 e 2011 pela Unesco, no Relatório de Monitoramento Global de Educação para Todos, que foi divulgado nesta quarta-feira, 29. [...]. O País é o $8^{\circ}$ entre os dez que concentram a maior parte $(72 \%$, no total) do número de analfabetos adultos do mundo, que é de 774 milhões, junto com 
Índia, China, Paquistão, Bangladesh, Nigéria, Etiópia, Egito, Indonésia e República Democrática do Congo. [...]. Dados da Pesquisa Nacional por Amostra de Domicílios (Pnad) 2012 mostram que, no segundo ano do governo Dilma Rousseff, a taxa de analfabetismo da população com 15 anos ou mais parou de cair e teve leve alta. Em 2011, era de 8,6\%. Chegou a 8,7\% em 2012, mais longe de cumprir a meta firmada na ONU de $6,7 \%$ até 2015. (SANTOS E AZAREDO, 2013, p. 1).

\section{REFERÊNCIAS}

ALIGHIERI, Dante. A Divina Comédia. São Paulo: Atena, 2003. Disponível em:<http://www.dominiopublico.gov.br/download/texto/eb00002a.pdf>. Acesso em: 10 out. 2013.

BARBOSA, Luciane Muniz Ribeiro. Estado e educação em Martinho Lutero: a origem do direito à educação. Cadernos de Pesquisa. [online]. 2011, v.41, n.144, p. 866-885. ISSN 0100-1574. Disponível em: <http:// www.scielo.br/pdf/cp/v41n144/v41n144a12.pdf>. Acesso em: 31 out. 2013.

BARBOSA, Luciane Muniz Ribeiro. As concepções educacionais de Martinho Lutero. Educ. Pesqui. [online]. 2007, vol.33, n.1, p. 163-183. ISSN 1517-9702. Disponível em: <http://www.scielo.br/pdf/ep/v33n1/ a11v33n1.pdf>. Acesso em: 4 de nov. 2013.

BRASIL. Lei n0 9.394, de 20 de dezembro de 1996. Estabelece as Diretrizes e Bases da Educação Nacional. Brasília: Casa Civil/Subchefia para assuntos jurídicos, 1996. Disponivel em: <http://www.planalto.gov.br/ ccivil_03/leis/l9394.htm>. Acesso em: 29 jan. 2014.

CAMBI, Franco. História da Pedagogia. São Paulo: UNESP, 1999.

FRANCO JÚNIOR, Hilário. A Idade Média e o nascimento do Ocidente. 3.ed. São Paulo: Brasiliense, 1980.

HOBSBAWM, Eric. Sobre história. São Paulo: Companhia das Letras, 1998.
LE GOFF, JACQUES. A Bolsa e a Vida: economia c religião na Idade Média. São Paulo : Brasiliense, 2004. Disponivel em: <http://www.submit.10envolve.com. br/uploads/0bd67fc2093588b2f9657b291e85395a. pdf>. Acesso em: 2 out. 2013

LIENHARD, Marc. Martim Lutero: tempo, vida, mensagem. São Leopoldo: Sinodal, 1998. Disponível em: <http:// books.google.com.br/books?hl=pt-BR\&lr=lang_es|lang_ en|lang_pt\&id $=8 \mathrm{gNekHdV=8-sC \& oi=fnd \& pg=P9A \& dq-}$ LIENHARD,+Marc.+Martim+Lutero:+tempo,+vida,+mensagem\&ots $=Q G 71$ r6K160\&sig=ipS5xsq_YFeraMK2zKzNIcJaTf4\#v=onepage\&q=LIENHARD\%2C\%20 Marc.\%20Martim\%20Lutero\%3A\%20tempo\%2C\%20 vida\%2C\%20mensagem\&f=false $>$. Acesso em: 31 out. 2013.

LOPES, Edson Pereira. 0 milenarismo dos Taboritas na Boêmia do século xv e sua influência no pensamento de João Amós Comenius. Ciências da Religião - História e Sociedade. São Paulo, v.5, n.2, 2007, p. 35-58, Disponível em: <http://editorarevistas.mackenzie.br/ index.php/cr/article/viewFile/485/307>. Acesso em: 28 out. 2013.

LUTERO, Martinho. 95 Teses. Wittenberg, 1917. Disponível em: <http://www.culturabrasil.org/zip/95teses.pdf>. Acesso em: 30 out. 2013.

LUZURIAGA, Lorenzo. História da Educação e da Pedagogia. 11.ed. São Paulo: Nacional, 1979.

RIETH, Ricardo Willy. André Osiander e o "Infanticídio em Pösing": alternativa no mundo anti-Semita da Reforma? Estudos Teológicos, América do Norte, 33, set., 2013, p. 62-73. Disponível em: <http://est. tempsite.ws/periodicos/index.php/estudos_teologicos/article/view/930/902>. Acesso em: 10 out. 2013.

ROSA, Maria da Glória de. A História da Educação através dos textos. São Paulo: Cultrix, 1971. 
SANTOS, Bárbara Ferreira; AZAREDO, Marina. Brasil não deve cumprir meta contra o analfabetismo. Estadão, São Paulo. Disponível em: <http://www.estadao.com.br/noticias/impresso,brasil-nao-deve-cumprir-meta-contra-o-analfabetismo,1124107,0.htm>. Acesso: 29 jan. 2014.

TILL, Eric. Lutero. [filme]. Alemanha/Estados Unidos, 2003. Produção de Alexander Thies, Brigitte Rochow, Christian P. Stehr, Dennis A. Clauss. Direção de Eric Till. Estados Unidos, MGM, 2003. 121 min. Disponível em: <http://www.youtube.com/watch?v=eezenm7Tlps>. Acesso em: 29 jan. 2014.
Recebido em: 29 de Janeiro de 2014 Avaliado em: 14 de Março de 2014 Aceito em: 15 de Março de 2014
VIANNA, Alexander Martins. Religião e ligação entre súditos e poderes soberanos (I): Martinho Lutero, paradoxo humano e autoridade secular. Espaço Acadêmico, Maringá, Eduem, vol. X, n. 117, Fev. 2011, p. 6282. Disponível em: <http://eduem.uem.br/ojs/index. php/EspacoAcademico/article/view/11691/6544>. Acesso em: 31 out. 2013.

1. Professora do curso de Pedagogia da UNIT/EAD. Mestre em educação pela Universidade Estadual de Maringá (UEM)/ Integrante do grupo de Pesquisa Arte, Educação e Contemporaneidade (ARCICO/GT/UFS-SE). Aracaju, Sergipe, Brasil, E-mail: monirela1@yahoo.com.br. 